\title{
A MATERNIDADE PREMATURA: O SUPORTE EMOCIONAL ATRAVÉS DA FÉ E RELIGIOSIDADE
}

\author{
Renata Meira Véras* \\ Juna Maria Fernandes Vieira \\ Fátima Raquel Rosado Morais
}

\begin{abstract}
RESUMO. Esse artigo objetivou desenvolver uma reflexão acerca do uso da espiritualidade/religiosidade pelas mães usuárias do Método Canguru numa maternidade conveniada ao Sistema Único de Saúde no Estado do Rio Grande do Norte. A perspectiva metodológica aplicada nesse estudo foi a pesquisa qualitativa, do tipo descritiva. Os dados foram apreendidos a partir da observação participante, das conversas informais, das entrevistas semi-estruturadas e da história de vida das mães, coletados nos encontros do grupo "Mães em Oração", desenvolvido pela equipe de enfermagem nessa maternidade. A análise mostrou que as práticas espirituais e a religiosidade atuam não apenas como suporte nas situações enfrentadas pelas mães na UTIN, mas abre uma possibilidade para o diálogo acerca da espiritualidade no ambiente hospitalar. Essa prática, ainda muito distanciada dos contextos das ações em saúde, contribui na humanização do cuidado, estreitando o vínculo entre mãe, filho, família e equipe multidisciplinar.
\end{abstract}

Palavras-chave: Método Canguru; religiosidade; humanização.

\section{PREMATURELY MOTHERHOOD: THE EMOTIONAL SUPPORT THROUGH FAITH AND RELIGIOSITY}

\begin{abstract}
This article aimed to develop reflection about the spirituality and religiosity use by mothers, users of Kangaroo Method in a Unified Health System (Sistema Único de Saúde) maternity in Rio Grande do Norte State. The approach used was the qualitative research, using participant observation, informal chats, semi directed interviews, and mothers' life story as procedure to data collection. Data were collected through meetings in Mothers in prayer (Mães em Oração), group developed by nursing team in this maternity. As the result, the analysis showed that the spiritual practice and the religiosity were used as a support in difficult situations at Neonatal Intensive Therapy Unit, as well as allowed the possibility to speak about spirituality in this maternity. This practice, even unconnected with everyday health care, contributes to humanize health care assistance, tightening the bond among mother, child, family and multidisciplinary team as well.
\end{abstract}

Key words: Kangaroo Method; religiosity; humanization.

\section{MATERNITAD PREMATURA: EL APOYO EMOCIONAL POR LA FE Y RELIGIOSIDAD}

RESUMEN. Este trabajo desarrolla una reflexión acerca del uso de la espiritualidad/religiosidad de las madres usuarias del método "Canguru" en una maternidad vinculada al Sistema Único de Salud en el Estado do Rio Grande do Norte. El enfoque metodológico fue la investigación cualitativa a partir de la observación participante, de las conversaciones informales, de las encuestas semi-estructuradas y de la historia de vida de las madres, recogidas en los encuentros del grupo "Mães em Oração". La análisis demostró que las prácticas y la religiosidad actúen no apenas como apoyo en las situaciones enfrentadas por las madres en la UTIN, pero abre en posibilidad para el dialogo a cerca de la espiritualidad en el ambiente hospitalero. Esta práctica, aun distanciada de los contextos de las acciones en salud, contribuye en la humanización de la atención, promoviendo el vínculo entre madre, hijo, familia y equipo multidisciplinatorio.

Palabras-clave: Método Canguro; religiosidad; humanización.

Psicóloga. Fisioterápeuta. Doutora em Psicologia Social, Brasil.

\# Licenciada em Ciências das Religiões. Técnica em enfermagem da Maternidade Escola Januário Cicco/RN. .

II Enfermeira. Doutora em Psicologia Social. Professora da Faculdade de Enfermagem da Universidade do Estado do Rio Grande do Norte (FAEN/UERN), Brasil. 
A religiosidade vem sendo destacada como uma das formas mais utilizadas pela população para expressar e elaborar a integração das dimensões racional, emocional, sensitiva e intuitiva. Diante de momentos de doença ou perda do ente querido é notável o apelo à religião por parte dos familiares, através de promessas e orações que servem como fonte de esperança na sobrevivência do doente e como forma de suportar a situação (Boff, 2006; KüblerRoss, 2005; Vasconcelos, 2006). Portanto, sugere-se que o tema da religiosidade deva ser incorporado aos estudos acerca das propostas de políticas de assistência à saúde, uma vez que o sujeito deve ser compreendido, e preferencialmente assistido, a partir de seu contexto biopsicossocial.

Todavia, verifica-se que apesar de existirem estudos acerca das concepções maternas sobre o parto prematuro (Camargo, LaTorre, Oliveira, Quirino, 2004; Preyde, 2007; Souza et al., 2007, Souza et al., 2009), não existem pesquisas que abordem o sentimento de religiosidade que se destaca nas mães diante da prematuridade de seus filhos e da gravidade do seu quadro de saúde.

A discussão acerca da prematuridade, enfocando os processos subjetivos maternos em relação à esperança e medo da morte do bebê, apresenta-se como fundamental, tendo em vista o parto prematuro no Brasil corresponder a $61,4 \%$ das mortes neonatais no país (Victora, 2001). Além dos riscos de óbitos associados à idade gestacional, esses bebês são menos propensos à sobrevivência devido às complicações, infecções e lesões que podem desencadear paralisia cerebral, distúrbios oftalmológicos e neurológicos (Arestégui, 2002).

Após o nascimento de um bebê prematuro, a assistência convencional preconiza a internação desses recém-nascidos em Unidade de Terapia Intensiva Neonatal (UTIN), acabando por permanecerem em incubadoras por períodos prolongados. Este internamento pode perdurar de dias até meses ficando estes neonatos separados das suas mães. Essa situação comprovadamente acarreta um menor apego e pouco ou nenhum desenvolvimento do vínculo afetivo entre mãe e filho, desencadeando histórias freqüentes de maus tratos e negligências com os bebês, ao se integrarem ao ambiente familiar (Klaus \& Kennel, 1992).

Nessa perspectiva, a partir do alto índice de partos prematuros no país e do impacto desta condição no curso do desenvolvimento biológico, social e psicológico da criança, o governo Brasileiro publicou em 5 de julho do ano de 2000 a portaria 693/GM, estabelecendo as Normas de Orientação para a Implantação do Método Canguru.

O Método Canguru foi proposto pela primeira vez no ano de 1979 pelos neonatologistas Hector Martinez e Edgar Rey Sanabria do Instituto Materno Infantil (IMI) de Bogotá, na Colômbia. A idéia surgiu em resposta ao elevado índice de mortalidade entre os recém-nascidos prematuros, cuja principal causa de óbito era a infecção hospitalar. Assim, visando à redução de gastos hospitalares e do índice de mortalidade neonatal, esses médicos utilizaram a mãe como substituta da incubadora.

No Brasil, o Método Canguru é aplicado preferencialmente nos hospitais do Sistema Único de Saúde revestido sob a retórica da humanização no atendimento ao recém-nascido prematuro e/ou de baixo peso. Assim, adota-se a prática de colocar o bebê em contato pele a pele com sua mãe, no intuito de fortalecer o vínculo mãe-bebê, incentivar o aleitamento materno e promover maior segurança nos cuidados com o filho (Véras \& Traverso-Yépez, 2010).

Esse método é aplicado através de três fases: A primeira refere-se ao tratamento na Unidade de Terapia Intensiva Neonatal (UTIN). Nesse período, a mãe passa a residir no alojamento conjunto e recebe orientações para realizar ordenha e incentivar a amamentação de bebês. A segunda fase ocorre na enfermaria Canguru, quando a mãe, já acompanhada do seu neonato, passa a adotar a posição pele a pele, sendo recomendada a permanência por 24 horas por dia nessa posição, até a alta do bebê. A terceira e última etapa corresponde ao apoio ambulatorial, após a alta do recém-nascido. Nesse momento a maternidade deve oferecer acompanhamento médico ao bebê até completar um ano de idade (Carvalho \& Prochnik, 2001).

$\mathrm{Na}$ maioria das maternidades do país, as mães, geralmente de baixa renda familiar e proveniente de áreas rurais, passam a residir no alojamento conjunto do Método Canguru até a alta do bebê. Esse período de mudança domiciliar pode perdurar de semanas até meses, dependendo da evolução clínica do prematuro. No geral não há suporte social por parte do governo e, muitas vezes, nem da própria família, o que pode contribuir para que as mães desenvolvam um quadro de tensão, demonstrando choro, sintomas depressivos ou até agressividade (Véras \& Traverso-Yépez, 2010).

A partir da vivência com as mães de bebês prematuros em uma maternidade que adota a prática do Canguru, foi possível observar um apelo religioso por parte das mães para justificar e tranqüilizar a família e, em particular, a si própria, diante da situação 
de risco do filho. A espiritualidade é apontada como uma das fontes primordiais de esperança, desempenhando um papel fundamental de sustentação do homem ao ajudar a superar e compreender o processo da doença e da morte (Boff, 2006).

$\mathrm{Na}$ pesquisa desenvolvida por Moura e Araújo (2005) verificou-se nos relatos das mães usuárias deste serviço a presença do uso da religiosidade para descrição das ocorrências no parto e internação da criança, assim como para minimizar o impacto emocional vivenciado na situação.

Nesse sentido, este artigo objetiva analisar as formas como a religiosidade e/ou espiritualidade são desenvolvidas e vivenciadas pelas mães usuárias do Método Canguru da Maternidade Escola Januário Cicco na Cidade de Natal-RN. Esse estudo visou também analisar a relação que se estabelece entre religiosidade e a diminuição do estado de tensão e estresse das mães que tem seus filhos internados na UTIN.

\section{METODOLOGIA}

Trata-se de uma pesquisa de campo realizada durante um ano na Maternidade Escola Januário Cicco na Cidade de Natal - RN. A amostra foi constituída por oito mães residentes no alojamento conjunto do Método Canguru que estavam acompanhando seus bebês prematuros internados na UTIN.

Como método para esse estudo, utilizou-se a pesquisa qualitativa do tipo descritiva, tendo a observação participante, conversas informais, entrevistas semi-estruturadas e história de vida das mães como procedimento na elaboração dos dados coletados (Minayo, 2004). As observações e entrevistas foram realizadas durante e após o grupo de orações e envolveram tópicos relacionados ao medo da morte do filho, a cultura religiosa da mãe e suas práticas, a importância da religião e da fé durante o internamento do filho na UTIN.

Esse grupo denominado "Mães em Oração" foi criado em 2007 pela equipe de enfermagem da maternidade com o objetivo de proporcionar conforto espiritual, comungar com Deus na fé e na esperança, como também compartilhar experiências das mães usuárias do método.

Após a coleta dos dados, os discursos foram transcritos e realizadas leituras sucessivas do material. As categorias foram construídas mediante as repetições das idéias, levando-se em consideração o objeto desta investigação. Da apresentação dos dados do estudo, e em respeito aos aspectos éticos das pesquisas que envolvem seres humanos, os nomes das mães foram identificados através de flores para contextualização dos relatos.

Numa descrição preliminar das mães participantes da pesquisa, grande parte delas possui baixo nível de escolaridade, baixa renda econômica e encontra-se na faixa etária entre 13 e 40 anos. Eram usuárias do Sistema Único de Saúde, advindo, em sua maioria, das cidades circunvizinhas a Natal que não possuem serviço de UTI neonatal. Cinco mães-canguru eram de origem religiosa católica não praticante, duas evangélicas e apenas uma praticava o pentecostalismo. Poucas mães relataram seguir uma religião, entretanto, a maioria acreditava em várias entidades religiosas, consideradas símbolos e imagens seculares do catolicismo.

\section{RESULTADOS}

Os resultados obtidos a partir dos discursos da pesquisa de campo foram divididos em quatro grupos de categorias analíticas, escolhidas diante dos temas abordados com mais freqüência: 1) Impacto ao ver o filho internado na UTI neonatal - a fé contribuindo para superação do medo da morte; 2) Buscando explicações divinas para o nascimento prematuro do filho; 3) Esforço para salvar o bebê - promessas para o Pai ajudar nesse momento; 4) Esperança e fé em Deus ajudando na recuperação do filho.

Impacto ao ver o filho internado na UTI neonatal - a fé contribuindo para a superação do medo da morte

O parto prematuro causa sempre um grande impacto para os familiares, que geralmente não esperam o nascimento tão precocemente. Os pais quase sempre idealizam a chegada do novo integrante ao seio familiar como momento de saúde e alegria (Brasil, 2002). No entanto, quando o recém-nascido é encaminhado para a UTIN, mãe e filho são separados, causando sofrimento para toda a família, como destaca o discurso de uma mãe:

Toda mãe quando tem o seu filho, pensa logo em segurar o seu filho. Mas isso não foi possivel porque logo depois que eu tive, ele já foi direto para UTIN, por nascer antes do tempo e também por problemas respiratórios (Tulipa, católica).

Diante da prematuridade, da gravidade do quadro do neonato e da necessidade da mãe se afastar do filho, era evidente a utilização de estratégias religiosas como consolo para as situações advindas com o nascimento antes da hora. É válido ressaltar que essa 
necessidade permeia os diferentes atores que vivem no contexto familiar. Os estudos de Tronchin e Tsunechiro (2006) apontam que, do mesmo modo que a mãe, o pai se apega aos aspectos divinos na esperança de salvar a vida do filho prematuro.

Assim sendo, tendo em vista o sentimento de impotência experimentado pelas mães na contribuição da recuperação do filho, a utilização da religiosidade serviu como amparo e esperança na sobrevivência do bebê:

Para mim foi um choque ver meu filho todo roxinho, sem respirar. As pessoas massageando para ele respirar. Tive vontade de desistir, desesperada, pois estava vendo meu filho morrer, e não podia fazer nada, só chorar e confiar em Deus que é nosso pai (Tulipa, católica).

Eu vi meu filho parar de respirar nos meus braços! Foi horrível, pois eu pensei que ele ia morrer, ele todo roxinho, fiquei desesperada. Aí, levaram meu filho para o oxigênio, e aos poucos ele foi voltando ao normal. Foi mais um grande susto, vocês não sabem o que é isso. Peçam a Deus que isso nunca aconteça com os filhos de vocês (Jasmim, evangélica).

O sentimento de medo e insegurança que as mães demonstram ao se depararem com a situação do seu filho geralmente surge a partir do pavor diante do desconhecido e da morte, do futuro incerto e da possibilidade de não retornar para sua casa com a criança tão esperada. Todavia, apesar das dificuldades, há um sentimento de esperança por parte dessas mulheres, sendo os filhos considerados como bênçãos, só pelo fato de terem sobrevivido. Mesmo diante da prematuridade, as mães já os caracterizavam como lutadores pela vida, guerreiros capazes de sobreviver pela intervenção de Deus.

Mas como o nosso Pai é maior, eu tive o meu bebê às 17h25min horas. Para mim foi a maior graça recebida por Deus, eu era mãe, meu filho tinha nascido que felicidades meu Deus! Que maravilha! Ao mesmo tempo eu me preocupava, chorava muito, pois o meu bebê nasceu sem oxigênio e com o lábio leporino, quanta angústia, pois sabia que ele ia passar por um grande sofrimento e teria uma batalha a superar, pois imaginei que fosse um grande "Guerreiro". E um grande guerreiro passar por tudo isso e sobreviver é uma benção dada por Deus (Violeta, católica).
Para Boff (2006), através da esperança se atribui um significado à existência, a esperança é a busca pelo sentido da vida, mesmo diante da morte. No cotidiano da mãe canguru, percebe-se que este sentimento é o que mais conforta as mesmas, no enfrentamento da morte. Segundo elas, a esperança e a fé, mesmo com tantas adversidades, promovem um alívio diante da realidade vivenciada e acabam favorecendo a aceitação de uma situação insatisfatória e trágica.

\section{Buscando explicações divinas para o parto prematuro do filho}

De acordo com Moraes (2008), durante o enfrentamento da doença é comum a presença de pensamentos e perguntas do tipo porque isso está acontecendo comigo, na tentativa de encontrar uma justificativa para as intercorrências. Percebeu-se nos discursos das mães este mesmo tipo de indagação, entretanto, atrelado a um questionamento em relação ao poder de Deus: "Onde está o senhor que não vê o meu sofrimento?" (Cravo, católica).

Foi o meu primeiro filho e eи peguei em meus braços uma só vez, como é gostoso agente poder pegar o nosso filho nos braços. Antes eu chegava, acariciava os pezinhos, as mãos dele, eu sentia que ele sabia que eu estava ali, mas hoje, ele apenas olhou para mim e fechou os olhinhos. Acho que ele está perto de terminar a missão dele aqui na terra, que foi tão curta... acho que ele nunca foi meu, e sim de Deus... Me dá um sentimento de perda, de fracasso, pois eu não gerei um filho capaz de viver, de atuar no meio social e eu fico me perguntando: Por que meu Deus? Aonde eu errei? O que faltou? (Violeta, católica)

Senhor me perdoa, mas quando eu a vi tão pequena, não tive muita fé, aquela pequena com dedinhos tão pequenos, respirando com tanta dificuldade com ajuda de aparelhos o tempo já passando e a dificuldade de permanência minha aqui dentro aumentou, pois me sentia prisioneira e me perguntava por que? (Margarida, católica)

Nesses discursos torna-se evidente o sentimento de perda diante da possível "inevitabilidade" de algumas situações agravadas pelo quadro clínico da criança. Isso favorece a ansiedade, muitas vezes, potencializada pelo isolamento do seu convívio social.

Conforme dito anteriormente, a maioria das mães usuárias do Método Canguru é proveniente das áreas rurais circunvizinhas à Natal. Por serem geralmente de classe social menos favorecida, e não receberem 
suporte do governo para o transporte e outras necessidades sociais e de saúde. Essas mulheres raramente recebem visitas dos seus familiares. Esse distanciamento de sua rotina e do seu convívio social acaba agravando a tensão e sentimentos de solidão. A busca por explicações divinas era um recurso bastante utilizado por essas mães:

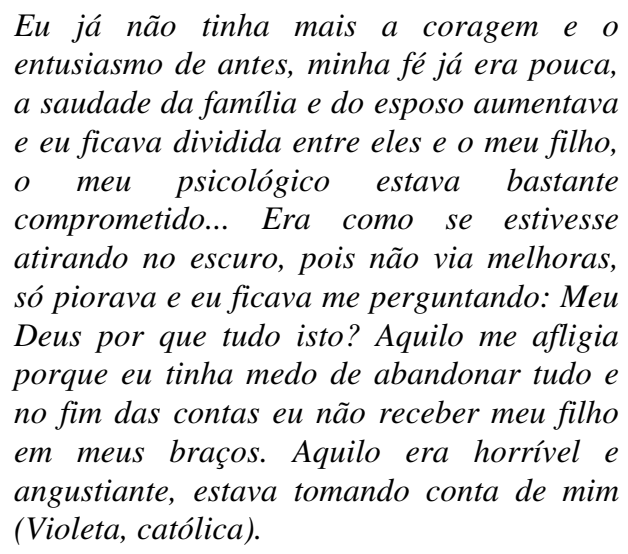

De acordo com Winnicott (2001), a mãe que atende às necessidades do bebê, acentuando o cuidado com o ambiente que o circunda, está colaborando para uma vida cheia de significados e vínculos afetivos satisfatórios. Entretanto, no cotidiano da maternidade, e com os prematuros em especial, essa situação não representa a realidade. Essas mães lidam com uma situação especial: a possibilidade da morte do bebê. Por esse motivo, verifica-se que muitas delas relatam se sentirem divididas entre voltar para casa sozinha ou continuar morando na maternidade investindo sentimentos num bebê que provavelmente poderá falecer. Assim, é possível refletir acerca da dificuldade de estabelecimentos de vínculo e da criação do apego diante do risco de morte, pois o medo de sofrer, e também do desconhecido, pode gerar reações de abandono e exclusão. Além disso, as questões maternas e a preocupação com crianças deixadas em casa, acaso o prematuro não seja o primeiro filho, tende a favorecer a vontade de ir para o seu lar e ficar com os que estão em casa.

Então cabe sugerir que estas mulheres precisam, além do apego religioso, discutir e refletir os sentimentos, diante da prematuridade, que transformam as suas vidas e práticas, caminhando entre extremos, do amor e da doação, ao desejo-de desapego e abandono.

\section{Esforço para salvar o bebê - promessas para o Pai ajudar neste momento}

Constatou-se que, seguindo as recomendações dos profissionais, as mães passavam a visitar o bebê com grande freqüência na UTIN, contribuindo para sua recuperação. Além deste esforço, também havia a apelação a Deus para salvar a vida do seu filho. Foi constatado nas observações e nas entrevistas que, durante as visitas das mães aos filhos na UTIN, promessas ao "pai divino" eram feitas, tornando-se a esperança de socorro para melhora do bebê:

Eu fiz tudo para tentar salvar a vida do meu filho, pois eu confio em Deus que ele vai vencer, pois ele é vitorioso em nome de Jesus, e vai ser pregador da palavra de Deus... É isso que me dá força para ficar a todo instante com ele (Dália Vermelha, católica).

Todos os meus dias eram dedicados ao meu bebê, ficava horas e horas na UTIN olhando para ele, cantando, rezando, cheirando $e$ pedindo a Deus para que ele se recuperasse, mas é tudo muito lento e de repente, o quadro começou a se agravar (Violeta, católica).

Os discursos das mães, assim como os relatos de história de vida, destacam a religiosidade e espiritualidade como instrumentos de superação nos momentos de dor, de angústia, de perda do sentido da vida, bem como de sustentação para a não compreensão do fenômeno da morte e o morrer.

Acrescenta-se que além destes sentimentos, há a necessidade de "barganha" com o "Pai" que salva, sendo a promessa este instrumento de troca e acordo com Deus. No imaginário destas mulheres pedir algo ao Pai, dando algo em troca, retribuindo um favor, tende a fazê-las crer mais no processo de cura, e isso pode ajudar na salvação, e consequentemente, na recuperação do seu filho.

\section{Esperança e fé em Deus ajudando na recuperação do filho}

Além do impacto do nascimento prematuro do filho, essas mães também lidavam com a internação prolongada na UTI neonatal, trazendo angústia e dúvidas quanto à recuperação do bebê. $\mathrm{O}$ recurso à espiritualidade em seus discursos retratava a esperança na sobrevivência do filho, minimizando o impacto emocional desta situação: "Mas eu tenho fé em Deus que vou sair daqui com meu filho e vou ter a vitória que tanto almejo que é ver meu filho comigo em casa" (Jasmin, evangélica).

A mãe Acácia depositou a fé em Deus para curar seu filho acreditando intensamente no poder de cura do pai divino: "Não suporto mais ver meu filho todo furado, não vejo a hora de Deus operar e retirar toda 
doença de cima dele, pois ele é um menino especial para mim, vou amá-lo muito por ser meu segundo filho" (evangélica).

Em outros relatos também se enfatiza os discursos das mães que, por não entenderem a situação clínica dos seus filhos, e menos ainda as explicações recebidas, acabavam recorrendo à fé em Deus na esperança de cura e recuperação.

A infecção continua, foi trocado já três antibióticos e ainda não melhorou, mas tenho muita fé em Deus e em Nossa Senhora Aparecida que ele vai melhorar e vamos ficar pouco tempo na UTIN, logo meu pequeno príncipe vai estar aos meus cuidados (Tulipa, católica).

Quando o vi naquele estado comecei a chorar bastante e pedi a Deus que não fosse nada grave. Passei o dia que não conseguia falar com ninguém, mas à tarde resolvi perguntar a médica o porquê daquela febre e ela me falou que era infecção e ele talvez. saísse do oxigênio. Foi aí que eu vim agradecer a Deus, pois só ele é digno de toda honra e glória e todo louvor (Acácia, evangélica).

Nesses discursos, percebe-se a necessidade das mães em se apegarem a algo para poder acreditar que tudo ficará bem. Dessa forma, conclui-se que o apego se volta para a fé e a cura a partir da religiosidade, único instrumento ao alcance destas mulheres, como bem apontam Raad, Cruz e Nascimento (2006). Para essas pessoas, leigas no conhecimento biomédico, não é possível acreditar na cura apenas em face dos procedimentos técnicos. Ao contrário, é preciso crer em algo superior, capaz de salvar, diante da evidência da eminente morte do filho.

Geralmente as mães canguru se chocam no momento da morte do seu filho, mesmo sabendo que eles provavelmente irão falecer. $\mathrm{O}$ luto pela morte desses bebês é percebido pela tristeza que acompanha as mães na enfermaria. Os discursos a seguir foram de uma mãe que acompanhou seu bebê na UTIN por 40 dias, mas o seu filho veio a falecer:

Pedia a Deus que ele amenizasse, aliviasse e desse o descanso do meu filho o mais rápido possível... pois tenho certeza que o meu bem mais precioso, que é meu filho, não perdi, mas entreguei à Deus, ou melhor, eu acho que ele nunca foi meu, e sim de Deus (Violeta, católica).

\begin{abstract}
Agradeço a Deus por e tudo, apesar da dor da perda do meu filho, mas muito obrigado por tudo теu Deus, sei que o Senhor não nos dá um fardo que não possamos carregar e eu tenho certeza que não estava preparada para o peso da cruz. Tenho certeza de que meu filho será meu anjo da guarda que estará me guiando e ajudando em todos os momentos bons e ruins da minha vida (Violeta, católica).
\end{abstract}

Muitas mães lançam mão da religiosidade para amenizar o sofrimento na hora da morte do filho. Percebe-se que essa mãe recorre a Deus, idealizando seu filho como um anjo da guarda, resignando-se a respeito de sua morte. Constata-se assim que no cotidiano da mãe canguru, a religiosidade é o caminho para o conforto espiritual também no enfrentamento da morte.

\section{DISCUSSÃO}

Pensar no ambiente hospitalar como ambiente de satisfação é quase impossível para as mães de recémnascidos prematuros. $\mathrm{O}$ espaço da UTIN caracteriza-se como um emaranhado de máquinas na qual se insere minúsculos corpos. A crença em Deus e a fé em algo superior tornam-se necessárias para as mães sonharem com a recuperação dos seus filhos, especialmente pela dimensão da esperança presente com maior frequência nas questões religiosas do que nos aspectos técnicos da saúde. Assim, caso a morte aconteça, seria mais consolável por ter sido desejo divino (Fraga \& Pedro, 2004).

$\mathrm{O}$ apego religioso geralmente passa a ser o suporte para a aceitação deste momento, contribuindo para a existência e manutenção de grupos religiosos e/ou de orações nos alojamentos conjuntos e nas UTINS das maternidades. No caso da Maternidade Escola Januário Cicco há um grupo espiritual intitulado "Mães em Oração", que serviu muitas vezes de apoio emocional para estas mulheres, conforme verificamos nos relatos. Constatou-se assim que os sentimentos de medo e solidão, devido ao distanciamento familiar e social, foram amenizados ao serem compartilhados pelas outras mães nesse grupo.

Durante os encontros no grupo de oração, as mães se emocionavam bastante diante da reprodução de músicas religiosas, assim como ao ouvirem os relatos das outras mulheres que esperavam a cura dos seus filhos. A expressão das emoções, aliada à diminuição da ansiedade, tendia a auxiliá-las a manterem a confiança e a esperança na recuperação dos seus filhos. Foi possível observar também que as mães se 
comoviam com o sofrimento das outras, numa relação de identificação mútua, despertando a solidariedade, o respeito pelo outro que padece e o encorajamento para enfrentar situações de riscos.

Nessa perspectiva, é importante que os trabalhadores da saúde procurem atuar com foco na integralidade, compreendendo que a mãe do prematuro possui necessidades que extrapolam os limites do biológico, social e psicológico, ganhando contornos espirituais e sentimentais. Pessini e Bertachini (2006) apontam para a prática de um cuidado paliativo ancorado em uma abordagem global, fundamentada na preocupação com as necessidades espirituais dos pacientes e seus familiares. Essa dinâmica tenderia a contribuir enormemente para a vivência das situações desgastantes em todos os setores da vida.

O cuidado paliativo é uma abordagem que visa o aumento da qualidade de vida dos pacientes e familiares que apresentam risco de morte, através da prevenção e alívio do sofrimento (Pessini \& Bertachini, 2006). Além disso, é preciso potencializar a equipe de saúde na discussão da finitude do humano e na necessidade de entender que nestes casos, em particular, é imprescindível que saibam refletir e apoiar diante da palpável morte prematura. Nessa perspectiva, estas práticas se apresentam como valioso instrumento para minimizar o sofrimento das mães e familiares no ambiente hospitalar, bem como auxiliar os trabalhadores no trato com as questões da morte e do morrer na interação com as pessoas.

\section{ALGUMAS CONSIDERAÇÕES FINAIS}

Este estudo contribuiu para a discussão dos efeitos da espiritualidade no ambiente hospitalar e a reflexão das práticas religiosas como forma de incluir a mãe no seu meio social e espiritual. Dos relatos colhidos e observações participantes no caminho pesquisado concluiu-se que as práticas espirituais e a religiosidade, atuam não apenas como suporte nas situações enfrentadas pelas mães na UTIN, mas abre uma possibilidade para o diálogo sobre a espiritualidade no ambiente hospitalar. Essa prática, ainda muito distanciada dos contextos das ações em saúde, contribui na humanização do cuidado e atua estreitando o vínculo entre mãe, fillho, família e equipe multidisciplinar em torno da essência do humano. $\mathrm{O}$ cuidado fundamental do homem a partir da ênfase em sua dimensão espiritual contribui para o ser humano melhor (Boff, 2002).

É possível refletir ainda que a dimensão religiosa, no caso da morte pelas intercorrências advindas da prematuridade, contribui para a elaboração do luto e a aceitação deste momento e da sua finitude com menos angústia e ansiedade por parte das mães e/ou outros familiares. Assim, recursos desta ordem devem ser estimulados nos espaços da saúde na perspectiva de contribuir para a dinâmica do trabalho cotidiano e para a potencialização das relações estabelecidas nestes contextos.

Portanto, essa pesquisa pode contribuir para oferecer elementos para os profissionais da saúde em termos do reconhecimento da diversidade que permeia o universo das mães usuárias do SUS, e com isso, contribuir para o trabalho desses profissionais em formular e implementar ações respeitando as práticas religiosas dos cidadãos, o que poderá, enfim, estabelecer práticas dialógicas mais eficazes.

Finalmente, reafirma-se a possibilidade de continuar as pesquisas sobre o tema em questão e sugere-se a necessidade de debater em profundidade a temática da morte. Conforme observado durante a coleta da pesquisa, constatou-se a relevância de estudar a temática da morte para que o ser humano tenha a consciência de que ele é um ser finito. Ao se adquirir esse nível de consciência, o sofrimento e a angústia diminuem, passando assim, a aceitar mais facilmente a morte de um filho, o distanciamento da família entre outros.

\section{REFERÊNCIAS}

Arestégui, R. U. (2002). El Método Canguro em el Hospital Nacional Docente Madre Nino (HONADOMANI) "San Bartolomé". Paediatrica, 4(3), 41-46.

Boff, L. (2002). Saber cuidar: Ética do ser humano - compaixão pela terra. $9^{a}$ Ed. Petrópolis: Vozes.

Boff, L. (2006). Espiritualidade: um caminho de transformação. Rio de Janeiro: Sextante.

Brasil, Secretaria de Políticas de Saúde/ Área de saúde da criança (2002). Atenção Humanizada ao Recém-Nascido de Baixo Peso: método mãe-canguru - manual do curso. Brasília: Ministério da Saúde. Recuperado em 10 de junho de 2006 em http://www.fiocruz.br/redeblh/media/manualcanguru.pdf

Camargo, C. L., La Torre, M. P. S., Oliveira, A. F. V. R. \& Quirino, M. D. (2004). Sentimentos maternos na visita ao recém-nascido internado em Unidade de Terapia Intensiva. Ciência, cuidado $e$ saúde, 3(3), 267-275.

Carvalho, M. R. \& Prochnik, M. (2001). Método mãe-canguru de atenção ao prematuro (Coleção BNDS Social, Vol. 1). Rio de Janeiro: BNDES.

Fraga, I. T. G. \& Pedro, E. N. R. (2004). Sentimentos das mães de recém-nascidos prematuros: implicações para a enfermagem. Rev Gaúcha Enferm, 25(1), 89-97.

Klaus, M. H. \& Kennel, J. H. (1992). Pais/bebê: a formação do apego. Porto Alegre: Artes Médicas. 
Kübler-Ross, E. (2005). Viver até dizer adeus. São Paulo: Pensamento.

Minayo, M. C. S. (2004). O desafio do conhecimento: pesquisa qualitativa em saúde. ( $8^{a}$ ed.) São Paulo: Hucitec.

Moura, S. M. S. R. \& Araújo, M. F. (2005). Produção de sentidos sobre a maternidade: uma experiência no Programa Canguru. Psicologia em Estudo, 10(1), 37-46.

Pessini, L. \& Bertachini, L. (2006). O que entender por cuidados paliativos? São Paulo: Paulus.

Preyde, M. (2007). Mothers of very preterm infants: perspectives on their situation and a culturally sensitive intervention. Social work in health care, 44(4): 65-83.

Raad, A. J., Cruz, A. M. C. \& Nascimento, M. A. (2006). A realidade das mães numa unidade de terapia intensiva neonatal. PSIC Revista de psicologia da Vetor Editora, 7(2), 85-92.

Souza, N. L., Araújo, A. C. P. F., Azevedo, G. D., Jerônimo, S. M. B., Barbosa, L. M., Sousa, N. M. L. (2007). Percepção materna com o nascimento prematuro e vivência da gravidez com préeclâmpsia. Rev.Saúde Pública, 41(5):704-10.

Souza, N. L., Araújo, A. C. P. F, Costa, I. C. C., Carvalho, J. B. L. \& Silva, M. L. C. (2009). Representações de mães sobre hospitalização do filho prematuro. Rev.Bras. Enferm, 62(5):72933.
Tronchin, D. M. R. \& Tsunechiro, M. A. (2006). Prematuros de muito baixo peso: do nascimento ao primeiro ano de vida. Revista Gaúcha de Enfermagem, 28(1), 79-88.

Vasconcelos, E. (2006). Espiritualidade no trabalho em saúde. São Paulo: Hucitec.

Véras, R. M. \& Traverso-Yépez, M. A. (2010). A maternidade na política de humanização dos cuidados ao bebê prematuro e/ou de baixo peso - Programa Canguru.). Revista Estudos Feministas, 18(1).

Victora, C. G. (2001). Intervenções para reduzir a mortalidade infantil pré-escolar e materna no Brasil. Revista Brasileira de Epidemiologia, 4(1), 3-69.

Winnicott, D. (2001). Os bebês e suas mães. São Paulo: Martins Fontes.
Recebido em 03/08/2009

Aceito em 19/03/2010
Endereço para correspondência:
Renata Meira Véras. Rua Maria Clotilde Tavares de Albuquerque, 60, Castelo Branco, CEP 58050-005, João Pessoa-PB, Brasil.E-mail: veras@ufrnet.br. 